\title{
TRANSIÇÃO DEMOGRÁFICA E GASTO PÚBLICO: UMA ANÁLISE COMPARATIVA DE DIFERENTES CONTEXTOS
}

\section{DEMOGRAPHIC TRANSITION AND PUBLIC SPENDING: A DIFFERENT CONTEXTS COMPARATIVE ANALYSIS}

\author{
Giana Silva Giacomelli* \\ Fabiane Volpato Chiapinoto* \\ Pascoal José Marion Filho" \\ Kelmara Mendes Vieira ${ }^{\bullet}$
}

\begin{abstract}
Resumo: A transição demográfica é um processo pelo qual os países desenvolvidos já passaram, e os países em desenvolvimento estão passando. Trata-se de uma fase da dinâmica populacional, na qual uma sequência de ocorrências leva ao envelhecimento populacional e à estagnação do crescimento da população de um país. O presente trabalho tem como objetivo analisar comparativamente dados do Brasil, que apresenta características da terceira fase da transição demográfica, da França, Itália e Alemanha, países que já encontram-se na última fase da transição. Como característica de uma pesquisa descritiva, o benefício deste estudo está em oferecer informações que podem fundamentar pesquisas posteriores e tomadas de decisões em nível de gestão pública. Identificam-se importantes diferenças nos gastos públicos entre Brasil e os países europeus selecionados. Assim como, fica evidente que o Brasil encontra-se em momento de realizar investimentos direcionados a preparar a população para as oportunidades que a transição demográfica oferece.
\end{abstract}

Palavras-chave: Transição demográfica. Gasto público. Bônus demográfico.

Abstract: The demographic transition is a process by which the already developed countries passed, and developing countries are going through. It is a phase of population dynamics, in which a sequence of events leads to population aging and stagnant growth of the population of a country. This work aims to comparatively analyze data from Brazil, which has characteristics of the third stage of demographic transition, and France, Italy and Germany, countries that already are in the last phase of the transition. As characteristic of a descriptive research, the benefit of this study is to provide information that can support further research and decision making in public management level. They identify important differences in public spending between Brazil and selected European

\footnotetext{
* Doutoranda do Programa de Pós-Graduação em Administração da Universidade Federal de Santa Maria.

- Mestranda do Programa de Pós-Graduação em Administração da Universidade Federal de Santa Maria.

- Doutorado em Economia Aplicada pela Escola Superior de Agricultura Luiz de Queiroz da Universidade de São Paulo - USP (1997). Atualmente é Professor Titular - Nível Único (Classe E) da Universidade Federal de Santa Maria.

- Doutorado em Administração pela Universidade Federal do Rio Grande do Sul (2006). Atualmente é professora associada do Programa de Pós-Graduação em Administração - PPGA/UFSM.
} 
countries. As it is evident, that Brazil is in the moment of making targeted investments to prepare the population for the opportunities the demographic transition offers.

Keywords: Demographic transition. Public spending. Demographic bonus.

\section{INTRODUÇÃO}

As mudanças demográficas, na América Latina, vêm ocorrendo de forma abrupta, impondo-se como um desafio ao processo de desenvolvimento econômico dos países latino-americanos. Diferente do processo que se deu na Europa e na América do Norte, a transição demográfica nos países da América Latina, caracteriza-se por um processo contraído, no qual o acesso a serviços e recursos públicos torna-se cada vez mais restrito para toda a população. Já, na Europa e na América do Norte esse processo ocorreu de forma gradual (LEBRÃO, 2007).

Uma das consequências da transição demográfica é o envelhecimento populacional, que se configura como um desafio à gestão pública, na medida em que têm seus reflexos na economia do país, já que mudanças no perfil etário da população, representam alterações de suas características tanto em termos de consumo quanto de produção. Desta forma, dispor de meios que enfrentem essa situação de forma eficaz é indispensável para o desenvolvimento econômico da nação.

No Brasil, o envelhecimento da população é resultante da expressiva queda nos índices de mortalidade, entre as décadas de 40 e 60 e da acelerada redução da taxa de fecundidade, a partir dos anos 60 (LEBRÃO, 2007). Tal situação representa uma transformação não só do perfil etário da população, mas se reflete também no perfil de consumo e produção, assim como, altera as demandas sociais, impondo aos gestores públicos a necessidade de formular estratégias que se antecipem ao atendimento de tais necessidades, evitando que o desenvolvimento econômico do país seja penalizado pelo processo de transição demográfica (CAMARANO, 2014).

A formulação de políticas públicas de saúde, educação, mercado de trabalho e previdência, por parte dos gestores públicos, são direcionadas a segmentos da estrutura etária, consequentemente devem levar em conta o processo de transição demográfica (BRITO, 2007b). Tais políticas podem ser representadas pela composição do gasto público de um país e é indispensável que estejam fundamentadas na condição demográfica, afim de que sejam eficientes e garantam ou estimulem o alcance do desenvolvimento econômico.

A ocorrência gradual do processo de transição demográfica é característica dos países desenvolvidos, nos quais o processo iniciou lentamente e levou mais de 200 anos para chegar em sua fase final, onde o crescimento da população é nulo ou negativo e o perfil etário é elevado. No entanto, uma transição demográfica comprimida é característica de países em desenvolvimento, nos quais as consequências deste processo surgem em menos de 100 anos, é o caso do Brasil (LEBRÃO, 2007).

Essa diferença entre as formas de ocorrência da transição demográfica tem impacto importante na gestão pública dos países, uma vez que a transição gradual possibilita um prazo maior para formular estratégias e acompanhar os 
resultados de tais ações. No entanto, uma transição demográfica comprimida exige ações de curto prazo e muitas vezes não permite aos gestores públicos formularem estratégias que se antecipem aos desafios.

O Brasil encontra-se em plena fase de ocorrência da transição demográfica e, apesar de se dar de forma comprimida, a fase em que o país se encontra ainda traz oportunidades para enfrentar os desafios futuros. Uma vez que, no momento atual de transição no Brasil, o envelhecimento da população ativa ainda é maior do que o da população idosa, desta forma os gastos públicos podem ser direcionados a aproveitar esta oportunidade (MENDES et al. 2012).

O objetivo geral deste trabalho é analisar descritivamente a diferença da dinâmica populacional e dos gastos públicos europeus, onde a transição demográfica ocorreu de forma gradual, e do Brasil, onde a transição demográfica apresenta-se de forma comprimida. E, especificamente, comparar os gastos nos setores de saúde, previdência e educação, que sofrem influências da transição demográfica.

A contribuição deste trabalho está no fato de avaliar possibilidades de ações para vivenciar o processo de transição demográfica de forma eficiente e possibilitar, inclusive, o aproveitamento de oportunidades que esse processo pode proporcionar a uma nação. A proposição é de que conhecer as características de países que já passaram pelas quatro fases da transição possibilita a construção de estratégias devidamente fundamentadas. Decisões adequadas de gestão pública podem diferenciar uma vivência de transição mais "conturbada" de uma transição que representa apenas uma fase da dinâmica populacional.

As projeções atuais, para a composição etária da população brasileira, alertam para o fato de que a demanda por condições de vida adequadas à situação de envelhecimento populacional aumenta e continuará a aumentar em níveis cada vez maiores, a questão principal é como as diferentes esferas de governo enfrentarão essa realidade. Neste sentido, o papel da estratégia pública, em termos de definição de políticas que sejam eficientes, torna-se cada vez mais importante para enfrentar os reflexos sociais e econômicos oriundos da transição demográfica.

\section{REFERENCIAL TEÓRICO}

Nesta seção será tratada a transição demográfica, sua caracterização e fases, bem como os gastos públicos relativos a este processo.

\subsection{Transição demográfica: desafios e oportunidades}

A transição demográfica é caracterizada pela passagem de um regime demográfico em que as taxas de natalidade e mortalidade são altas para outro, em que estas taxas passam a reduzir e se tornam baixas. $O$ momento no qual ocorre essa alteração no perfil demográfico dos países permite classifica-los em três tipos: i) países com iniciação precoce; ii) países com iniciação tardia e; iii) países que ainda não iniciaram o processo de transição demográfica (LEBRÃO, 2007).

Basicamente estes três tipos podem ser representados respectivamente pelos países desenvolvidos; em desenvolvimento e os mais pobres. Nos 
primeiros, a transição demográfica teve início em finais do século XIX e início de século XX, atualmente encontram-se em fase avançada da transição em direção à fase pós-transição demográfica, França e Itália são bons exemplos. No segundo grupo de países o processo teve início em fins do século XX e início do século XXI, encontra-se em plena ocorrência, um exemplo de nação é o Brasil. Já no terceiro grupo tem-se o continente africano, que ainda não apresenta as características da fase inicial da transição demográfica, que são: manutenção das taxas de fecundidade e redução das de mortalidade (BRITO, 2007b).

A transição demográfica é constituída por quatro fases fundamentais, e é em posse do conhecimento destas fases e de suas características que a gestão pública deve formular ações eficientes que impactarão beneficamente nas fases posteriores. Brito (2007b) define as fases resumidas no Quadro 1.

\section{Quadro 1: Fases da transição demográfica}

\begin{tabular}{|c|c|}
\hline Fases & Características \\
\hline 1 Pré - transição demográfica & $\begin{array}{l}\text { - Altas taxas brutas de mortalidade e } \\
\text { natalidade; } \\
\text { - Baixo crescimento vegetativo }{ }^{1} \text { da } \\
\text { população. }\end{array}$ \\
\hline 2 Início da transição & $\begin{array}{l}\text { - Nível de mortalidade começa a cair, mas } \\
\text { o de fecundidade se mantém alto; } \\
\text { - Aumento sustentado do ritmo de } \\
\text { crescimento natural da população. }\end{array}$ \\
\hline $\begin{array}{l}3 \text { Incremento populacional a } \\
\text { ritmo decrescente }\end{array}$ & $\begin{array}{l}\text { - Declínio também das taxas de } \\
\text { fecundidade; } \\
\text { - Desaceleração do crescimento } \\
\text { demográfico. }\end{array}$ \\
\hline 4 Pós-transição demográfica & $\begin{array}{l}\text { - Baixos níveis de fecundidade e } \\
\text { mortalidade; } \\
\text { - Crescimento populacional lento ou } \\
\text { negativo. }\end{array}$ \\
\hline
\end{tabular}

Fonte: Elaboração própria com base em Brito (2007b).

Em países desenvolvidos, as fases de plena transição demográfica (fases 2 e 3) ocorreram de forma gradual permitindo melhor organização do ente público, enquanto que nos países em desenvolvimento ocorrem em um menor período de tempo. "O que ocorreu em mais de 200 anos na Europa Ocidental está acontecendo em poucas décadas na América Latina" (LEBRÃO, 2007, p.137).

No Brasil, a primeira vez que a taxa de crescimento populacional foi menor do que 1\%, segundo Mendes et al. (2012), foi em 2009, apresentando-se em $0,98 \%$. Mantendo-se a tendência de declínio do crescimento populacional, a

\footnotetext{
${ }^{1}$ Crescimento vegetativo é a diferença entre taxa de natalidade e a de mortalidade de um país (JANUZZI, 2007).
} 
previsão é de que a partir de 2040 as taxas de crescimento da população do país sejam negativas.

Desta forma, a projeção é que o processo de envelhecimento populacional, que levou em torno de 150 anos para ocorrer na Europa, ocorrerá em um prazo de aproximadamente 50 anos, no Brasil. Até o ano de 2000 o perfil etário da população brasileira constituía uma pirâmide, com maior parte da população na base, representando pessoas até 20 anos de idade. No entanto, a projeção para as próximas décadas é o aumento da população nos níveis superiores da pirâmide, representando o envelhecimento populacional.

Atualmente, o quadro demográfico brasileiro apresenta como características a redução da população menor de 15 anos (jovens), pequeno crescimento da população idosa e elevado crescimento da população ativa. Mendes et al. (2012) alerta para o fato de que é neste momento que um país deve aproveitar as oportunidades da transição demográfica, direcionando seus investimentos para o mercado de trabalho, seguridade social e para a saúde e educação das gerações que logo ocuparão este espaço, em uma sociedade que apresentará altas e sustentadas taxas de dependência de idosos. $O$ momento da transição demográfica que o país vive, com redução da taxa de dependência, decorrente do alto crescimento da população em idade ativa, redução da população jovem e pequeno crescimento da população idosa, proporciona o chamado "bônus demográfico" ou "dividendo demográfico", neste momento o crescimento populacional tem efeito positivo sobre o crescimento econômico (PAIVA; WAJNMAN, 2005). Esta fase representa a oportunidade para o país promover políticas públicas eficientes para enfrentar a fase seguinte, de estabilização do crescimento da população ativa, início do envelhecimento populacional e consequente aumento da razão de dependência dos idosos.

É indispensável aproveitar a situação demográfica em que o crescimento da população ativa é maior do que das faixas "mais caras" à sociedade, a fim de preparar o país para enfrentar de forma eficiente as próximas fases deste processo, a qual traz, especialmente, os altos custos com saúde dos idosos. "A qualificação da futura força de trabalho torna-se componente imprescindível para um equilíbrio intergeracional, social e econômico, mais justo." (WONG; CARVALHO, 2006, p.5).

As taxas de dependência podem representar as alterações da estrutura etária de um país, desta forma, o índice que indica a razão de dependência pode ser utilizado como proxy da transição demográfica de uma região (WONG; MOREIRA, 2000). Além disso, Wong e Carvalho (2006) afirmam que se pode utilizar a mediana da idade da população, para avaliar o seu envelhecimento, no entanto, utilizam em seu trabalho a Razão de Dependência (RD) e o Índice de Idosos (II) para representar o envelhecimento populacional na América Latina.

$O$ índice de envelhecimento da população brasileira, elaborado pelo Instituto Brasileiro de Geografia e Estatística (IBGE), de acordo com Benício et al. (2015), evidencia o rápido avanço das transformações do perfil demográfico do país. A forma como se dão essas transformações exigem o acompanhamento rápido de mutações sociais e econômicas.

No caso do Brasil, o enfrentamento dos desafios da transição demográfica, de forma eficiente, exige, conforme Paiva e Wajnman (2005), o estímulo da geração de emprego feminino; a eliminação da discriminação no mercado de trabalho; extinção do trabalho infantil e; redução das atividades 
informais no mercado de trabalho. Além disso, é indispensável a redução da pobreza e da desigualdade, garantia do acesso à educação e à saúde para que a sociedade brasileira possa aproveitar o "bônus demográfico" a fim de aumentar a produtividade do país, e se organizar de tal forma que o envelhecimento populacional se torne apenas mais uma etapa do processo social, sem se caracterizar como um problema, proporcionando que a população ativa tenha condições de promover e manter o desenvolvimento econômico do país.

\subsection{Gasto público no contexto da transição demográfica}

A composição do gasto público representa o direcionamento de políticas públicas do governo, que quando formuladas de acordo com as características demográficas da população pode garantir a eficiência da gestão. As projeções de gastos públicos com educação, saúde e previdência evidenciam o impacto do envelhecimento populacional na condução da gestão pública (GRAGNOLATTI et al., 2011).

As finanças públicas das próximas décadas receberão impactos substanciais resultantes do aumento da longevidade da população, tal pressão será marcada não apenas pela necessidade de gerenciamento do gasto previdenciário, mas também pela necessidade de aumento do gasto público com saúde (BENíCIO et al., 2015). A literatura aponta que o Fundo Monetário Internacional (FMI) têm projeções de que os gastos relacionados ao envelhecimento populacional, em economias avançadas, no período de 2014 a 2030, aumentarão em torno de $3,8 \%$ do PIB, sendo que $74 \%$ deste crescimento está vinculado ao gasto com saúde e o restante com a previdência.

Com relação ao Brasil, as projeções do $\mathrm{FMl}$ apontam que, nos próximos 15 anos, a elevação dos gastos com saúde se dará em termos de 1,9\% do PIB, representando o segundo maior aumento entre os países emergentes e alertando para os desafios impostos pela mudança no perfil demográfico brasileiro (BENíCIO et al., 2015). Em países europeus, Erixon e Van Der Marel (2011) evidenciam que o gasto per capita com saúde, no período de 1960 a 2005, cresceu mais do que a renda per capita.

De acordo com levantamentos apresentados por Gragnolatti et al. (2011), quando os gastos do Brasil são comparados aos países da OCDE, os gastos públicos com educação e previdência, em percentual do PIB, não divergem muito dos países membros, no entanto, quando se trata de gasto público com saúde há uma divergência considerável. Benício et al. (2015) afirmam que apesar da despesa previdenciária ser a mais afetada pelo envelhecimento populacional, o gasto com saúde apresenta-se na situação mais crítica, uma vez que além de sofrer influência do fator demográfico, é impactado também pelo aumento dos custos dos serviços de saúde em geral.

Para Berenstein e Wajnman (2008), o envelhecimento da população está diretamente relacionado à alteração do perfil de morbimortalidade, impactando profundamente nos custos gerados na área da saúde.

Do ponto de vista da saúde, a transição demográfica está diretamente relacionada à transição epidemiológica, que se caracteriza, grosso modo, pela alteração do perfil de morbimortalidade antes marcado pela alta prevalência de doenças transmissíveis, para o predomínio das doenças crônico-degenerativas e causadas por fatores externos.

Revista de Estudos Sociais | Ano 2016, N. 37, V. 18, Pag. 169 
Nesse processo, modifica-se paulatinamente o perfil de saúde da população: ao invés de processos agudos que se resolvem rapidamente por meio da cura ou do óbito, tornam-se predominantes as doenças crônicas e suas complicações, que muitas vezes significam décadas de utilização dos serviços de saúde - medicamentos, consultas médicas e internações hospitalares de longa duração, resultando, consequentemente, em maiores gastos (BERENSTEIN; WAJNMAN, 2008, p. 2301).

De acordo com Nunes (2004), é possível identificar que a utilização de serviços de saúde apresenta diferentes níveis ao longo da vida, traduzindo-se em uma distribuição das despesas assistenciais que difere para cada faixa etária. Conforme autores como Nunes (2004) e Pinto e Soranz (2004), as fases da vida que apresentam maiores exigências de utilização dos serviços de saúde são os anos iniciais, especialmente os menores de 5 anos, e em seguida a faixa etária que compreende os indivíduos idosos, pessoas com mais de 60 anos.

Considerando o atual cenário da dinâmica populacional brasileira, é evidente a necessidade de realização de reformas estruturais que viabilizem financeiramente a prestação dos serviços de saúde e previdência. No entanto, é indispensável que sejam feitos também investimentos que objetivem a racionalização e eficiência do gasto público (BENíCIO et al., 2015).

O crescimento natural dos gastos associados ao envelhecimento da população poderá ser parcialmente compensado por economias geradas pela adoção de melhores práticas de gestão pública, que logrem os mesmos resultados com uma quantidade inferior de recursos públicos aplicados. Portanto, mais do que uma oportunidade, 0 aumento da eficiência do gasto público no Brasil é uma necessidade (BENíCIO et al., 2015, p. 48).

Enquanto os gastos com saúde e previdência são os mais visíveis, no âmbito da transição demográfica, os gastos com educação são inseridos neste contexto, na medida em que possibilitam que as oportunidades da transição possam ser aproveitadas, e o país enfrente o processo de envelhecimento de forma eficiente.

\section{METODOLOGIA}

O trabalho caracteriza-se como uma pesquisa descritiva, na medida em que objetiva comparar descritivamente as características de diferentes países, tendo como assunto central da análise a transição demográfica. Uma pesquisa descritiva apresenta as características de determinada população ou fenômeno, não tem como compromisso específico explicar os fenômenos descritos, mas servir de base para a elaboração desta explicação (VERGARA, 2011).

A pesquisa descritiva destina-se especialmente a medir características de um problema de pesquisa, e geralmente serve para direcionar um processo e fornecer informações sobre quais os aspectos devem ser mensurados, oferecendo o benefício de fundamentar decisões a serem tomadas (HAIR Jr., et al., 2005).

Adota-se uma abordagem analítica de categorias em particular, uma vez que, a partir dos dados apresentados realiza-se a comparação das características da dinâmica populacional e despesas públicas em diferentes países (PEREIRA, 2004). O trabalho utiliza representações visuais, como 
gráficos, figuras e quadros resumos para apresentar os dados que, de acordo com Pereira (2004), facilita o processo de análise, pois evita o excesso de informações, reduzindo as dimensionalidades, e facilita também a elaboração de conclusões.

Os países escolhidos para a análise foram: Brasil, por estar passando pelo processo de transição demográfica; França, Alemanha e Itália, como representantes dos países que já passaram por esse processo e, por isso, podem oferecer exemplos de direcionamento do gasto público para o Brasil.

A pesquisa analisou dados da dinâmica populacional e de gastos públicos, para analisar comparativamente as características de países europeus e do Brasil, tendo como foco o processo de transição demográfica, seu decorrente processo de envelhecimento populacional e as oportunidades possibilitadas pela transição demográfica.

A origem dos dados utilizados neste trabalho é, principalmente, o site da OCDE - Organização para a Cooperação e Desenvolvimento Econômico, no entanto, para algumas informações referentes ao Brasil foi necessário recorrer a outras fontes de informações, como o IBGE - Instituto Brasileiro de Geografia e Estatística e INEP - Instituto Nacional de Estudos e Pesquisas Educacionais Anísio Teixeira. No Quadro 2 é possível identificar a descrição e a fonte dos dados analisados para a construção dos resultados desta pesquisa, que serão apresentados no tópico a seguir.

Quadro 2: Descrição e origem dos dados

\begin{tabular}{|c|c|c|}
\hline Indicador & Descrição & Fonte \\
\hline $\begin{array}{l}\text { População total } \\
(1980-2012)\end{array}$ & $\begin{array}{l}\text { Número de pessoas que normalmente } \\
\text { vivem em um país. }\end{array}$ & $\begin{array}{l}\text { OCDE; } \\
\text { IBGE }\end{array}$ \\
\hline $\begin{array}{l}\text { População jovem } \\
(1980 \text { - 2012) }\end{array}$ & Pessoas com idade inferior a 15 anos. & OCDE \\
\hline $\begin{array}{l}\text { População idosa } \\
(1980-2012)\end{array}$ & Pessoas com 65 anos ou mais. & OCDE \\
\hline $\begin{array}{l}\text { População ativa } \\
(1980-2012)\end{array}$ & População com idade entre 15 e 64. & OCDE \\
\hline $\begin{array}{l}\text { Taxa de } \\
\text { fertilidade }(1980- \\
2012)\end{array}$ & $\begin{array}{l}\text { Número total de crianças nascidas por } \\
\text { mulher em idade fértil, por ano. }\end{array}$ & OCDE \\
\hline $\begin{array}{l}\text { Despesas com } \\
\text { saúde }(1995- \\
\text { 2010) }\end{array}$ & $\begin{array}{l}\text { Consumo final de bens e serviços de } \\
\text { saúde, somado ao investimento de capital } \\
\text { em infraestrutura de cuidados de saúde. }\end{array}$ & OCDE \\
\hline $\begin{array}{l}\text { Despesas ensino } \\
\text { superior } \\
(2000,2008- \\
2011)\end{array}$ & $\begin{array}{l}\text { Despesa total com o mais alto nível de } \\
\text { educação. }\end{array}$ & $\begin{array}{l}\text { OCDE; } \\
\text { INEP }\end{array}$ \\
\hline $\begin{array}{l}\text { Despesas com } \\
\text { pensões e } \\
\text { aposentadorias } \\
(2000,2005 \text { - } \\
2012)\end{array}$ & $\begin{array}{l}\text { Despesas de caixa (incluindo pagamentos } \\
\text { de montante fixo) direcionadas a idosos e } \\
\text { pensões de sobrevivência. }\end{array}$ & $\begin{array}{l}\text { OCDE; } \\
\text { DATAPREV }\end{array}$ \\
\hline
\end{tabular}

Fonte: Elaboração própria. 
A Razão de Dependência é um índice usualmente utilizado para representar a transição demográfica, por refletir o envelhecimento populacional (Wong; Moreia, 2000; Brito, 2007a, 2008). O presente artigo utilizou a Razão de Dependência Total, assim como RD Jovens e RD Idosos para melhor descrever as análises comparativas, todos os índices foram calculados com base nos dados constantes no Quadro 2.

\begin{abstract}
A estrutura etária pode ser analisada não só pela dinâmica, no tempo, dos seus grupos etários, mas, também, pela relação entre eles, ou, em outras palavras, pelas relações intergeracionais. Considerando os três grandes grupos etários, pode-se calcular a relação de dependência demográfica total (RDT): o número de jovens (população menor do que 15 anos) somado ao de idosos (população maior do que 65 anos), ou seja, aqueles, teoricamente dependentes, divididos pela população em idade ativa (população entre 15 e 65 anos), aqueles teoricamente produtivos. Tem-se, então, a razão de dependência total, que pode ser considerada através de seus componentes, a razão de dependência dos jovens (RDJ = população menor de 15 anos dividida pela PIA) e a razão de dependência dos idosos (RDI = população de 65 anos ou mais de idade dividida pela PIA). Serão utilizados, nessa análise, esses dois componentes da razão de dependência total, em porcentagem (BRITO, 2007a, p.17).
\end{abstract}

Além da Razão de Dependência, também foram calculados, para elaborar os gráficos e realizar as análises, o percentual de idosos e o percentual de jovens no total da população, com base nos dados obtidos através da OCDE.

Para o cálculo das despesas com o ensino superior, no total das despesas com educação, foi necessário utilizar o banco de dados do INEP, para obter as informações sobre o Brasil. A fonte de dados também foi diferente no caso dos dados sobre aposentadorias e pensões para o Brasil, neste caso, utilizou-se o DATRAPREV para obter o valor das despesas com aposentadorias, pensões e benefícios a idosos e, além disso, foi necessário fazer o comparativo com o PIB brasileiro em $\mathrm{R} \$$, que foi obtido através do site do IBGE.

\title{
4. RESULTADOS E DISCUSSÃO
}

Com relação à dinâmica populacional, é possível identificar, nos gráficos 1, 2 e 3, que a partir dos anos de 1985, na França e na Itália, e 1986, na Alemanha, a participação da população idosa no total da população começa a aumentar, ao contrário da participação da população jovem, que se reduz desde o início da década de 1980. Tal situação é refletida pelo aumento da Razão de Dependência Total (RDT), a partir da década de 1990, nestes países.

Os gráficos 1, 2 e 3 permitem, ainda identificar que no Brasil, na mesma época, também ocorre a variação negativa do percentual de jovens, e positiva do percentual de idosos, na população, no entanto, o país apresenta, no período que vai de 1980 até os anos 2000, uma taxa de fertilidade acima do índice de reposição, de 2,1 filhos por mulher (BLOOM et al., 2003), que pode ser visualizada no Gráfico 4. Desta forma, em comparação com os países europeus analisados, já tinha a característica de um país mais jovem. Enquanto o percentual de idosos na população da França, Itália e Alemanha, em 1980, era em torno de $15 \%$, o Brasil tinha apenas um percentual de $4 \%$ de idosos quando 
esse grupo etário começou a aumentar sua representatividade no total da população brasileira.

Gráfico 1: Percentual da população idosa sobre o total da população

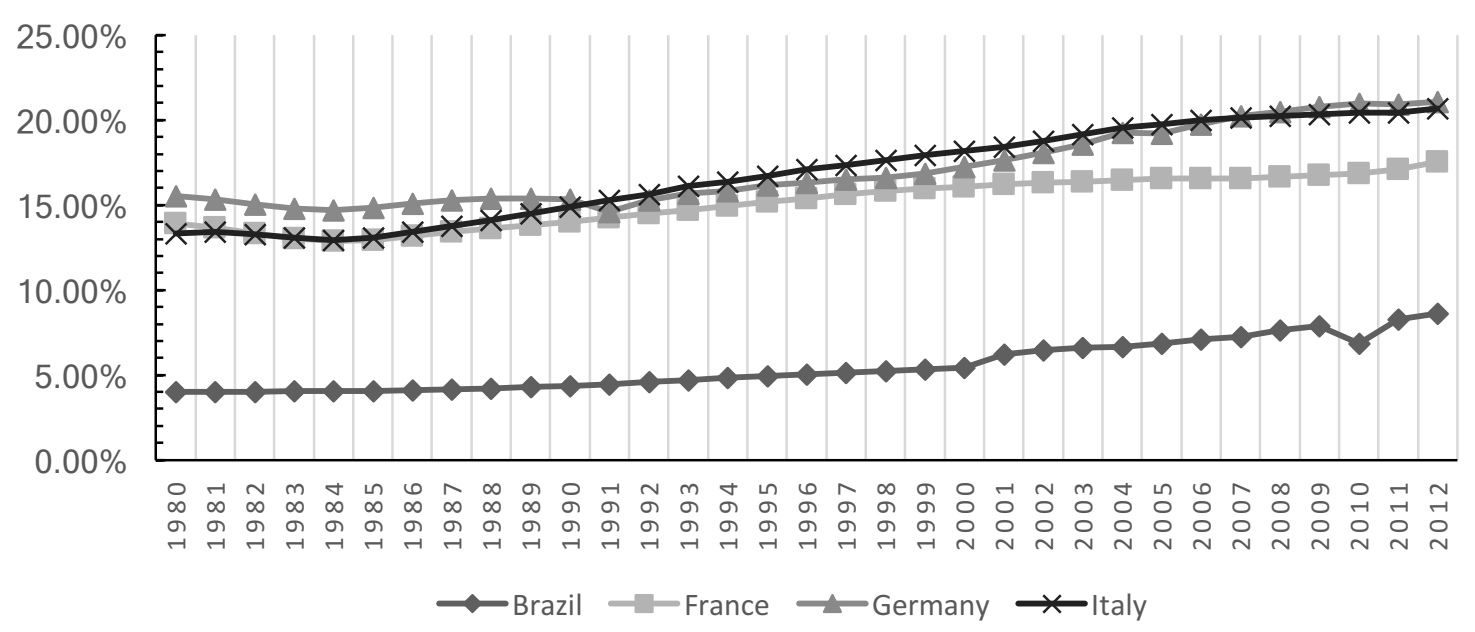

Fonte: Elaboração própria com base nos dados da OCDE.

Gráfico 2: Percentual da população jovem sobre o total da população

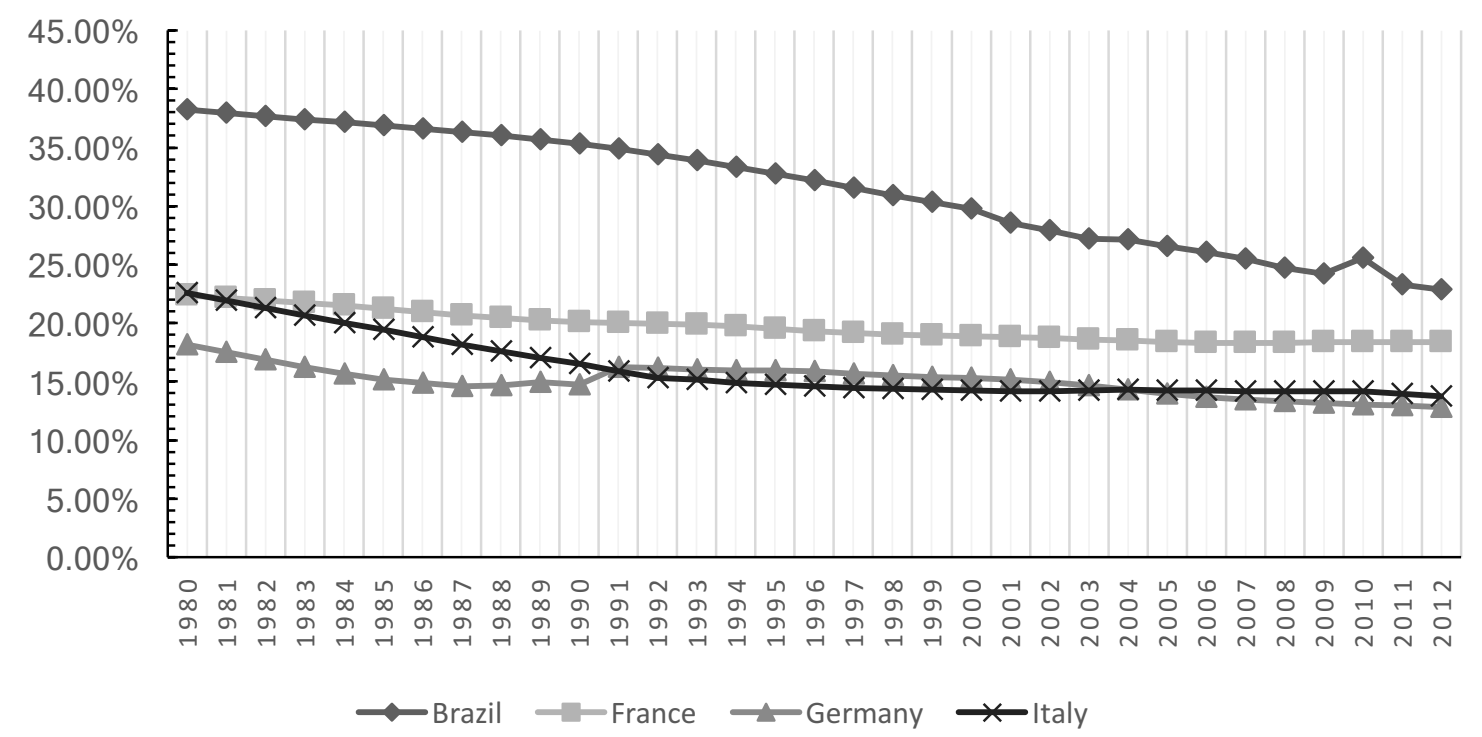

Fonte: Elaboração própria com base nos dados da OCDE.

Gráfico 3: Percentual da população jovem (até 15 anos) e idosa (acima de 65 anos) sobre o a população ativa (16 a 64 anos) 


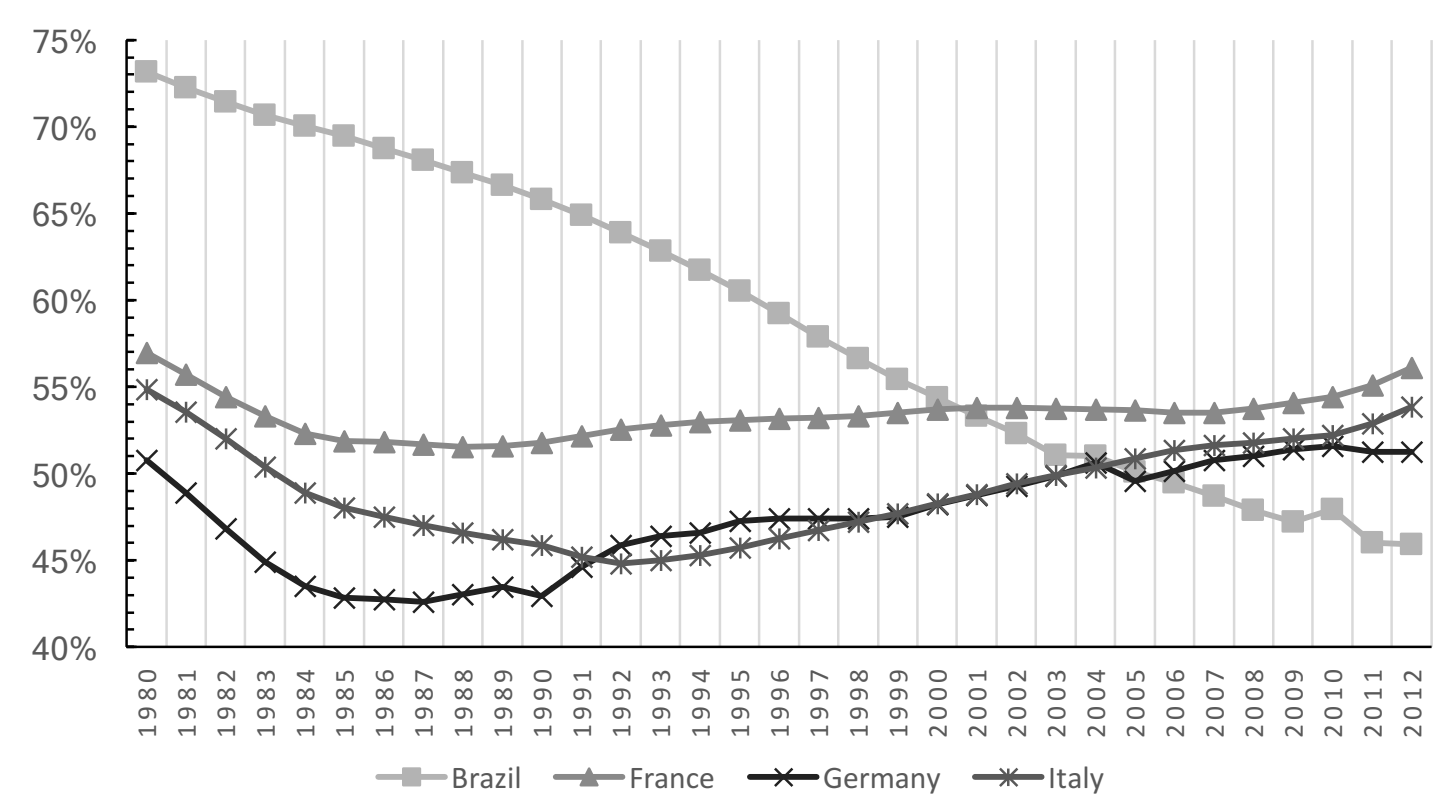

Fonte: Elaboração própria com base nos dados da OCDE.

O aumento da RDT nos países europeus, visualizado no Gráfico 3, reflete a fase em que estes países passam a depender mais de sua população ativa, ou seja, o crescimento da população dependente, influenciada pelo aumento do número de idosos, torna-se maior do que o crescimento da parcela produtiva da população, característica da última fase da transição demográfica. No Brasil, a Razão de Dependência Total ainda apresenta uma queda, entre 1980 e 2010, acompanhada pela queda na taxa de fertilidade, apresentada no Gráfico 4, indicando que a redução da população jovem é seguida pelo aumento da população ativa, visualizado no Gráfico 5 , ainda que seja uma elevação menos abrupta, reflete um país com menor índice de dependentes.

No entanto, é possível identificar que a partir de 2010 essa redução já é menos intensa; a população ativa estabiliza, e o país, que na década de 1980 tinha uma alta Razão de Dependência Total influenciada pela população menor de 15 anos, em breve terá uma retomada do crescimento desta relação, mas influenciada pelo aumento de pessoas com mais de 65 anos na composição populacional, observado com maior intensidade a partir do ano de 2000. 


\section{Gráfico 4: Taxa de fertilidade}

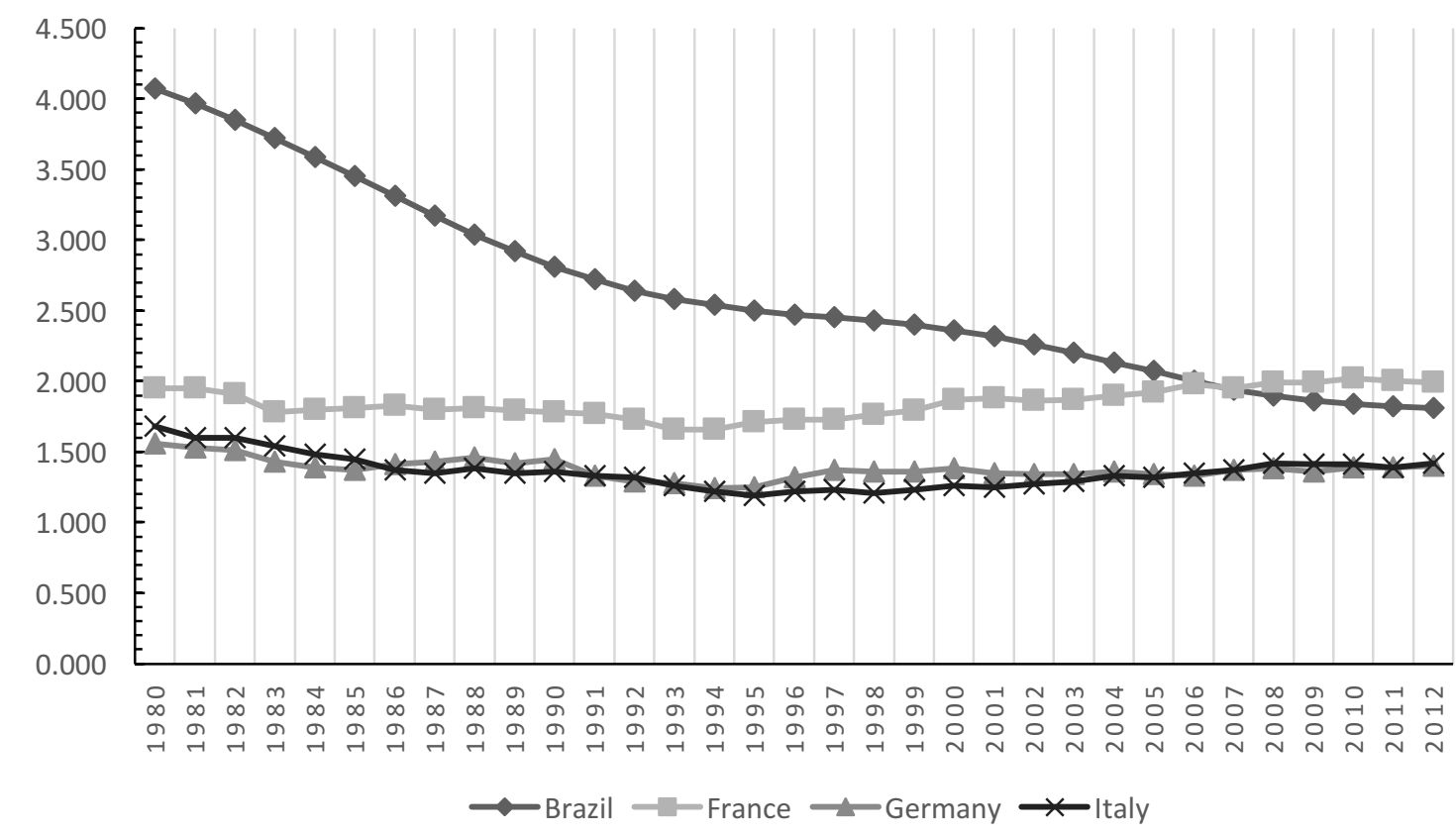

Fonte: Elaboração própria com base nos dados da OCDE.

\section{Gráfico 5: Percentual da população ativa sobre o total da população}

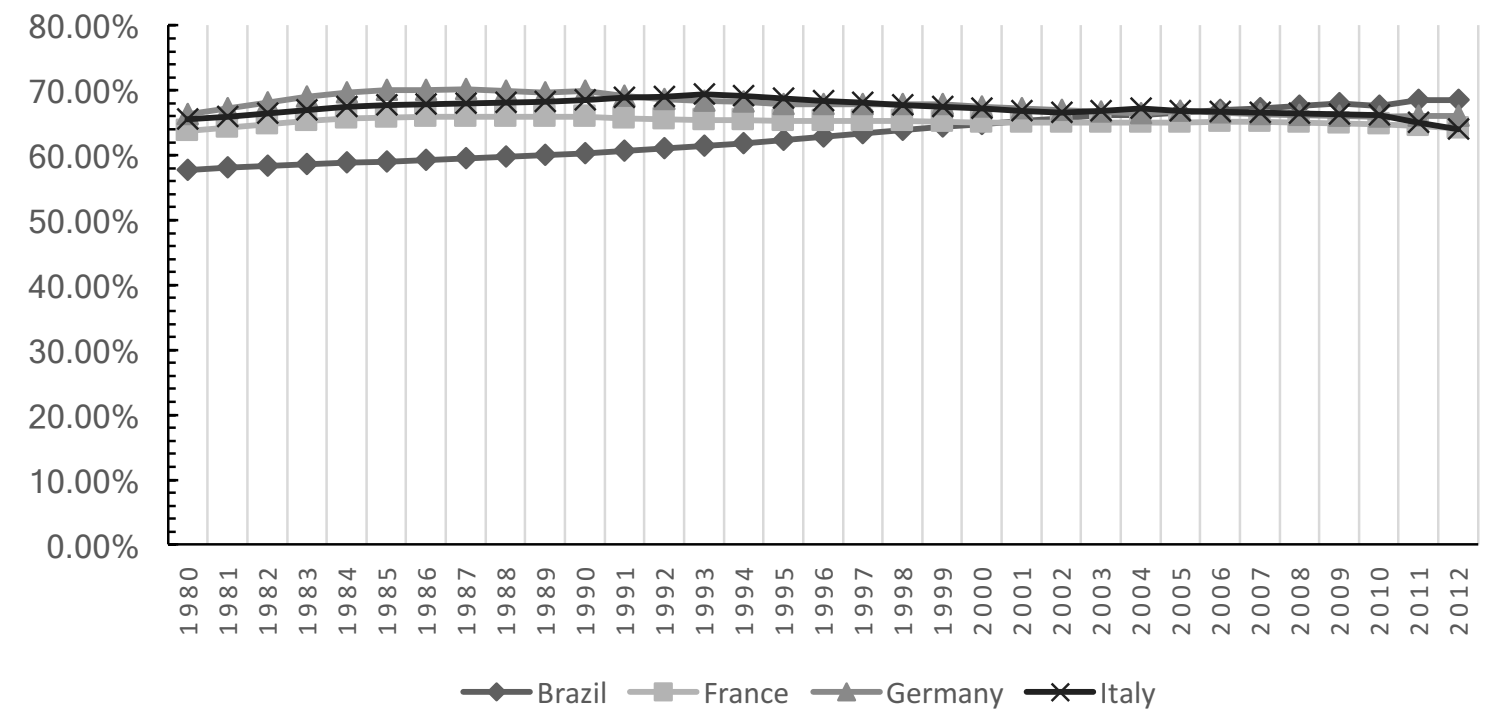

Fonte: Elaboração própria com base nos dados da OCDE.

O início da transição demográfica na França, Itália e Alemanha tem suas origens antes mesmo da década de 80 , uma vez que a taxa de fertilidade, nestes países, apresentou-se menor que o índice de reposição desde a década de 70 , acompanhado pela redução nas taxas de mortalidade infantil também nesta época. O Brasil, somente após o ano de 2004 , atingiu os níveis de mortalidade 
infantil e fecundidade que os países europeus em questão apresentavam em 1970. Tal fato oferece a possibilidade de acompanhar o histórico de gastos públicos que podem ter influenciado e colaborado com os países europeus para enfrentar os desafios da transição demográfica.

Dentre as despesas que sofrem maior influência da transição demográfica, devido ao envelhecimento populacional decorrente deste processo, estão as despesas com saúde e previdência. As diferentes fases da transição também podem influenciar nas despesas públicas, por exemplo, o Brasil encontra-se na terceira fase, a de incremento populacional a ritmo decrescente (Britto, 2007b), na qual a população economicamente ativa cresce com uma variação superior às parcelas dependentes, momento no qual o país tem a possibilidade de preparar a sua população para enfrentar 0 envelhecimento sem maiores dificuldades, direcionando investimentos, não só em previdência e saúde, mas também em educação.

Para Bloom et al. (2003) ações positivas direcionadas à educação, família, aposentadoria, participação feminina e mercado de trabalho, possibilitam mudanças sociais e representam 0 bom aproveitamento do dividendo demográfico. $O$ presente trabalho manteve o foco na análise de despesas públicas com saúde, previdência e educação.

Comparando os gastos públicos com saúde da França, Itália e Alemanha com os do Brasil, é possível identificar no Gráfico 6 que os países europeus, no período de 1995 a 2012, mantiveram um gasto anual médio de 7\% do seu PIB direcionado para a saúde pública. Enquanto o Brasil, no mesmo período, apresentou uma média anual de $3 \%$ do PIB direcionados à saúde. Muitas avaliações podem ser elaboradas a partir destes indicadores, uma delas é a compreensão de que uma população mais envelhecida, como a dos países europeus analisados, exige maiores investimentos em saúde.

\section{Gráfico 6: Despesas com saúde}

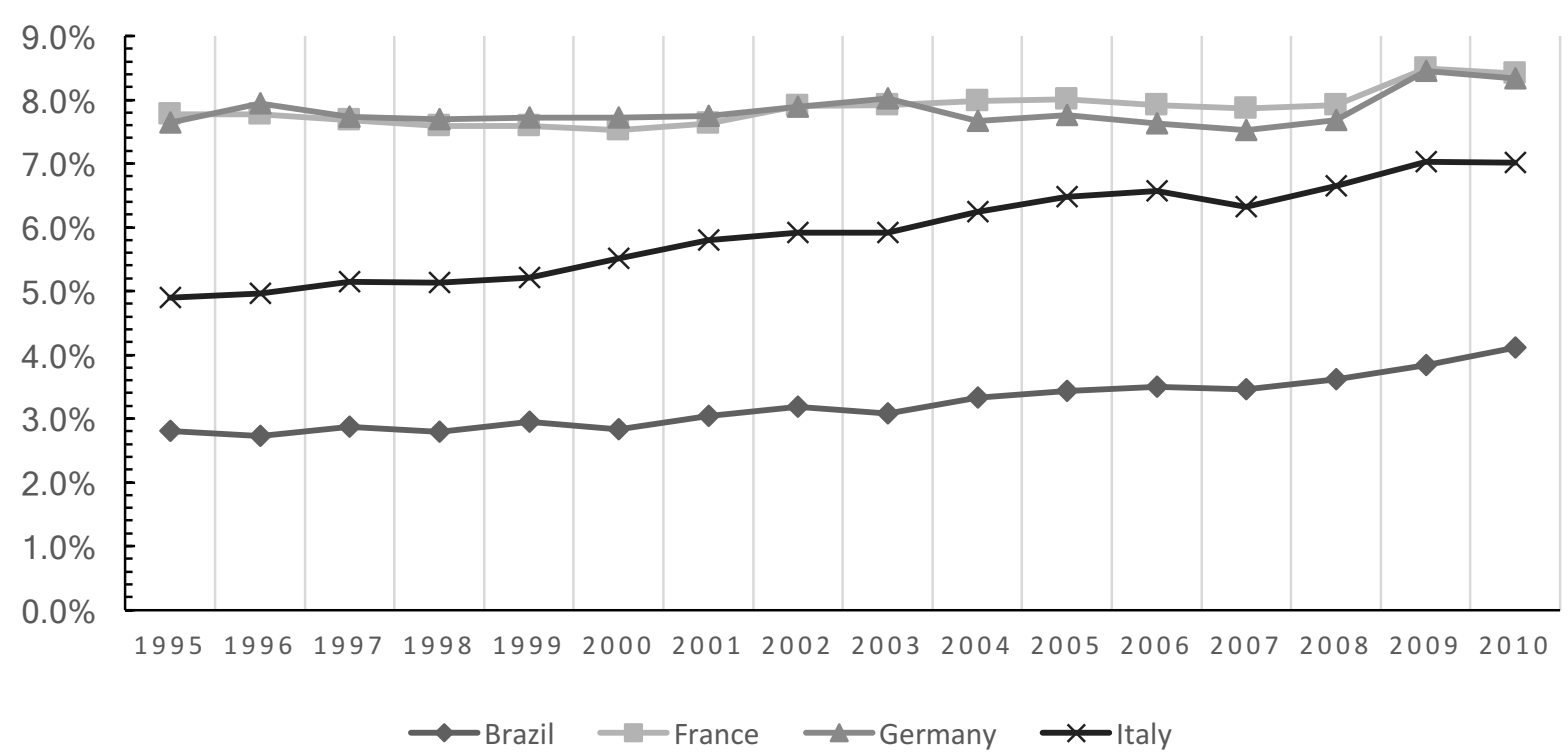

Fonte: Elaboração própria com base nos dados da OCDE. 
Quando se trata de despesas com pensões e aposentadorias, apresentadas no Gráfico 7, o Brasil também fica consideravelmente abaixo da média anual dos países escolhidos, que é de $12,6 \%$ do PIB, para $6,1 \%$ do PIB, no Brasil. Este indicador, inquestionavelmente, também é influenciado pelo perfil etário da população, e serve para a gestão pública brasileira projetar seus gastos nesta área quando a população estiver na última fase da transição demográfica, na qual França, Alemanha e Itália encontram-se, considerando o período analisado para este indicador (2000 a 2009).

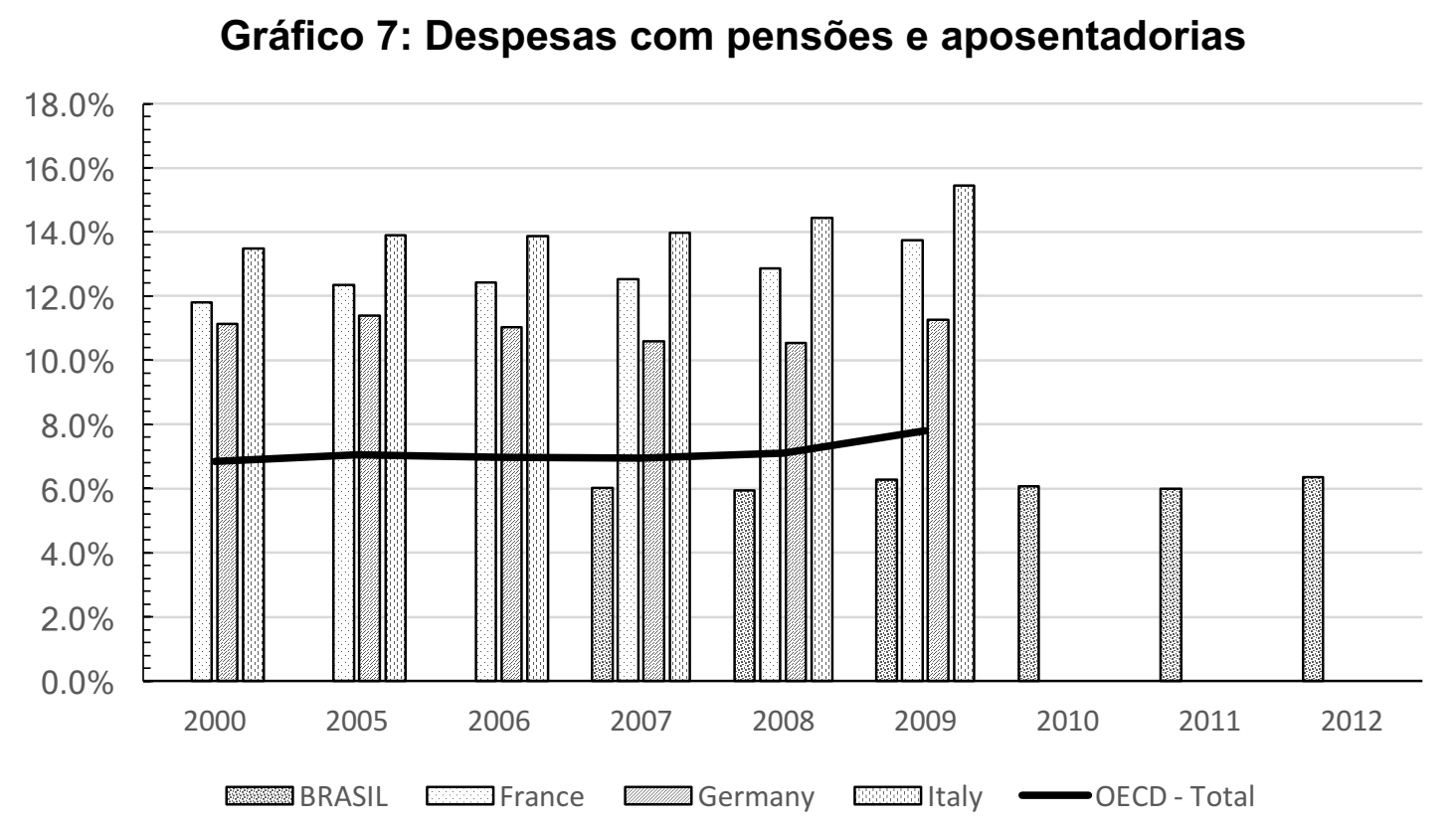

Fonte: Elaboração própria com base nos dados da OCDE e DATAPREV.

Os gastos com educação superior foram pesquisados neste trabalho devido ao reconhecimento da influência da transição demográfica no mercado de trabalho. De acordo com Bloom et al. (2003), a correlação positiva entre educação e salários é conhecida, e pode ser exemplificada pelo caso da América Latina, onde seis anos de estudos garantem ao trabalhador um salário $50 \%$ maior do que aquele sem educação formal.

O aumento da produtividade é uma das oportunidades oferecidas pela transição demográfica, no entanto é necessário que o país e a população estejam preparados para aproveitar tal oportunidade. Em termos de gastos com o ensino superior, com relação ao total dos gastos com educação, é possível identificar que o Brasil encontra-se muito abaixo do perfil da França, Itália e Alemanha. Enquanto mais de $80 \%$, na França e na Alemanha, e mais de $70 \%$, na Itália, dos gastos com educação são direcionados ao nível superior, no Brasil, o percentual fica em torno de $15 \%$. Tal diferença, provavelmente, não pode ser explicada pelo perfil etário da população, o Brasil, tendo uma crescente população em idade ativa deveria prepara-la da melhor forma para o mercado de trabalho, garantindo que o país enfrente a fase subsequente da transição demográfica de forma eficiente. 


\section{Gráfico 8: Despesas com ensino superior sobre o total das despesas com educação}

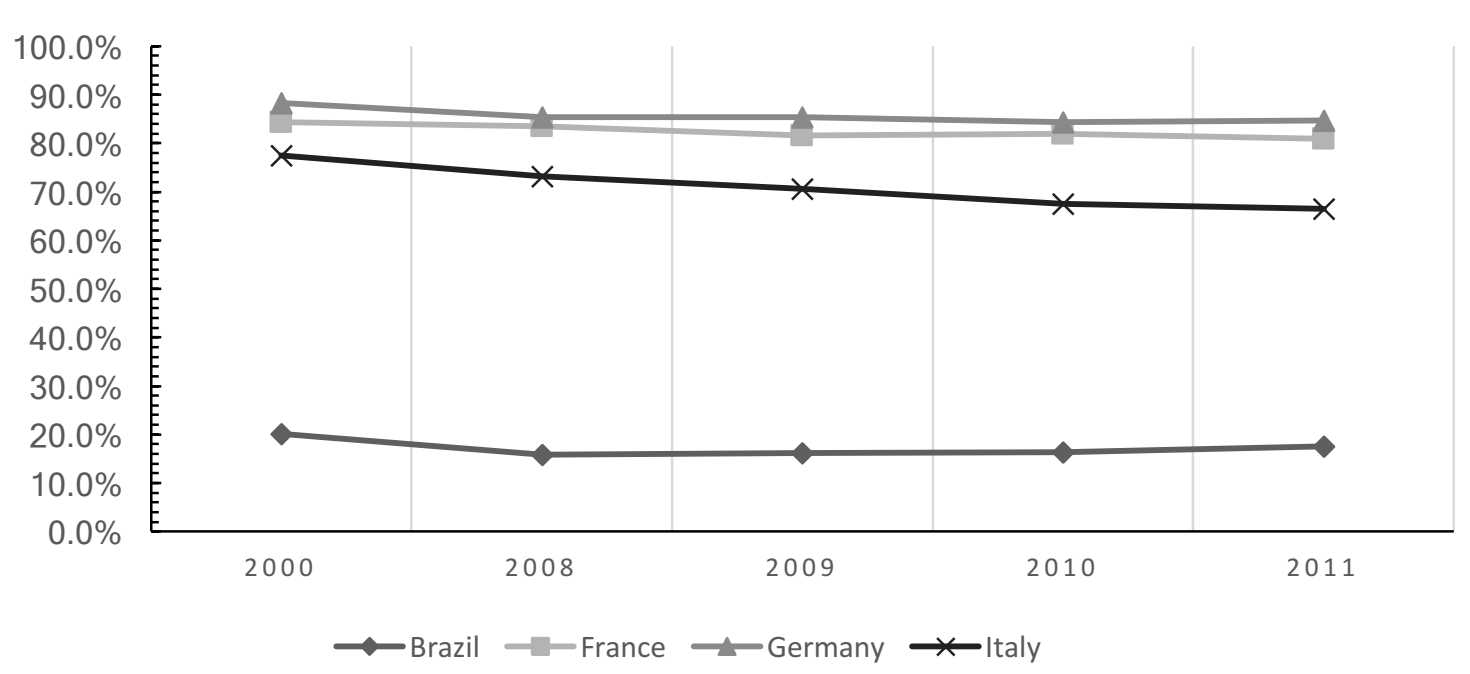

Fonte: Elaboração própria com base nos dados da OCDE e DATAPREV.

A transição demográfica exerce influência sobre o mercado de trabalho, principalmente por duas frentes: o envelhecimento da população ativa e a participação da mulher no mercado (Bloom et al., 2003). As mulheres com menor número de filhos, criadas em famílias menores, com mais acesso à educação tendem a entrar também no mercado de trabalho, participando do aumento da produtividade (Bloom et al., 2003). Na fase de incremento populacional a ritmo decrescente, na qual o Brasil se encontra, a transição oferece a oportunidade de aumento na produção per capita, desde que o país tenha condições de absorver a oferta crescente de mão de obra, decorrente do aumento da população ativa.

\section{CONCLUSÃO}

O presente trabalho apresentou como objetivo realizar a comparação entre os dados das características populacionais e do gasto público de um país que encontra-se na terceira fase da transição demográfica e países que já passaram desta fase e já convivem com os resultados da ocorrência do processo da transição.

O objetivo foi atendido através da análise comparativa de dados, obtidos principalmente a partir do site da OCDE - Organização para a Cooperação e o Desenvolvimento Econômico, possibilitando a construção de uma base de conhecimento para posteriores pesquisas e servindo como informativo em termos de gestão pública.

Dentre os limites da presente pesquisa está a ausência de todos os dados para o mesmo período de tempo, especialmente de dados sobre as despesas públicas, e a abrangência apenas descritiva dos resultados. Como sugestão, para futuros trabalhos, propõe-se a realização de analises mais profundas e não apenas descritivas, que possibilitem comprovar a correlação entre a transição demográfica e o gasto público em saúde, previdência e educação, e, inclusive 
que permitam demonstrar a importância do investimento em educação superior para aproveitar o "bônus demográfico".

Apesar dos fatores limitadores, a presente pesquisa permite evidenciar que o Brasil encontra-se em um período importante da dinâmica populacional, no qual a população ativa ainda cresce em maior volume do que as parcelas dependentes da população. Tal fato alerta para que os gestores realizem investimentos públicos, especialmente em educação, para que essa fase possa ser aproveitada e gere benefícios econômicos que garantam que a próxima fase da transição demográfica seja enfrentada de forma eficiente, sem apresentar-se como um problema, mas como uma característica de um país que se aproxima do desenvolvimento.

\section{REFERENCIAS BIBLIOGRÁFICAS}

BENÍCIO, A.P.; RODOPOULOS, F.M.A.; BARDELLA, F.P. Um retrato do gasto público no Brasil: por que se buscar a eficiência. Capítulo 1. P. 19 - 52. In: BOUERI, R.; ROCHA, F.; RODOPOULOS, F.M.A. (Org.) Avaliação da qualidade do gasto público e mensuração da eficiência. Brasília: Secretaria do Tesouro Nacional, 2015.

BERENSTEIN, C. K.; WAJNMAN, S. Efeitos da estrutura etária nos gastos com internação no Sistema Único de Saúde: uma análise de decomposição para duas áreas metropolitanas brasileiras. Cad. Saúde Pública. Rio de Janeiro, v. 24 , n. 10 , p. 2301-2313, out/2008.

BLOOM, D. E.; CANNING, D.; SEVILLA, J. The demographic dividend: a new perspective on the economic consequenses of population change. Santa Monica, CA: RAND, 2003.

BRITO, F. A transição demográfica no contexto internacional. Texto para discussão; 317. Belo Horizonte, UFMG/CEDEPLAR, 2007a.

BRITO, F. A transição demográfica no Brasil: as possibilidades e os desafios para a economia e a sociedade. Texto para discussão; 318 . Belo Horizonte, UFMG/CEDEPLAR, 2007b.

BRITO, F. Transição demográfica e desigualdades sociais no Brasil. Revista Brasileira de Estudos de População. São Paulo, v. 25, n. 1, p. 5-26, jan./jun. 2008.

CAMARANO, A. A. (org.) Novo regime demográfico: uma relação entre população e desenvolvimento? Rio de Janeiro: IPEA, 2014.

DATAPREV - Empresa de Tecnologia e Informações da Previdência Social. Disponível em: < http://portal.dataprev.gov.br/>. Acesso em: set. 2015

ERIXON, F.; VAN DER MAREL, E. What is driving the rise in health care expenditures? An inquiry into the nature and causes of the cost disease. 
ECIPE working paper.European Centre for International Political Economy, n. 5, 2011.

GRAGNOLATI, M. et al. Growing old in na older brazil implications of population ageing on growth, poverty, public finance and service delivery. The world bank. Washinton, D.C. 2011.

HAIR Jr, J. F. et al. Fundamentos de métodos de pesquisa em administração. Tradução: Lene Berlon Ribeiro. Porto Alegre: Bookman, 2005.

IBGE - Instituto Brasileiro de Geografia e Estatística. Disponível em: < http://www.ibge.gov.br/home/estatistica/indicadores/pib/pib-volval_201501_8.shtm>. Acesso em: set. 2015.

INEP - Instituto Nacional de Estudos e Pesquisas Educacionais Anísio Teixeira. Disponível em: < http://portal.inep.gov.br/estatisticas-gastoseducacao >. Acesso em: set. 2015.

JANUZZI, P. M. Cenários futuros e projeções populacionais para pequenas áreas: método e aplicação para distritos paulistanos 2000-2010. Revista Brasileira de Estudos de População. São Paulo, v. 24, n. 1, p. 109-136, jan./jun. 2007.

LEBRÃO, M. L. O envelhecimento no Brasil: aspectos da transição demográfica e epidemiológica. Saúde Coletiva, v. 4, n.17, p.135-140, 2007.

MENDES, A. C. et al. Assistência pública de saúde no contexto da transição demográfica brasileira: exigências atuais e futuras. Cadernos de Saúde Pública. Rio de Janeiro, v.28, n.5, p.955-964, mai, 2012.

NUNES, A. O envelhecimento populacional e as despesas do Sistema Único de Saúde. Os Novos Idosos Brasileiros: Muito Além dos 60? Org. Ana Amélia Camarano. Rio de Janeiro: IPEA, 2004. Disponível em: < http://ipea.gov.br/agencia/images/stories/PDFs/livros/Arq_21_Cap_13.pdf >. Acesso em: out. 2015.

OCDE - Organização para a Cooperação e o Desenvolvimento Econômico. Disponível em: < https://data.oecd.org/ >. Acesso em: out. 2015.

PAIVA, P. T. A.; WAJNMAN, S. Das causas às consequências econômicas da transição demográfica no Brasil. Revista Brasileira de Estudos de População. São Paulo, v. 22, n. 2, p. 303-322, jul./dez. 2005

PEREIRA, J. C. R. Análise de dados qualitativos: Estratégias metodológicas para as ciências da saúde, humanas e sociais. 3. Ed. São Paulo: Editora da Universidade de São Paulo, 2004.

PINTO, L. F.; SORANZ, D. R. Planos privados de assistência à saúde: cobertura populacional no Brasil. Ciência \& Saúde Coletiva, v. 9, n. 1, p. 8598, 2004. 
VERGARA, S. C. Projetos e relatórios de pesquisa em administração. 13. Ed. São Paulo: Atlas, 2011.

WONG, L. L. R.; CARVALHO, J. A. O rápido processo de envelhecimento populacional do Brasil: sérios desafios para as políticas públicas. Revista Brasileira de Estudos de População. São Paulo, v. 23, n. 1, p. 5-26, jan./jun. 2006.

WONG, L. R.; MOREIRA, M. M. Envelhecimento e desenvolvimento humano: As transformações demográficas anunciadas na América Latina (1950-2050) [Resumo]. In F. Lozano Ascencio (Ed.), Anais de la VI Reunión Nacional de Investigación Demográfica en México: Balance y Perspectivas de la Demografía Nacional ante el Nuevo Milenio (pp. 31). México, DF: Universidad Nacional Autónoma de México, 2000. 